\title{
Urban visions: Back from the future
}

\author{
Olivier Chamel $^{1}$ \\ ${ }^{1}$ Florida A\&M University, School of Architecture and Engineering Technology, Tallahassee, \\ Florida, USA
}

\begin{abstract}
The persistent growth of the human civilization, fueled in large part by technological progress has brought upon us a series of very serious challenges. The quality of our overall environment, energy and food supply are subjected to increased pressure, while access to decent employment, housing and medical care remains broadly unequal. According to the current trends most of the world's future population growth will occur in cities, therefore positioning the city as a key component to solving challenges associated with human development. Based on that assumption, it seems crucial to think about what the city of the future should be and look like. If we look for existing and graphically convincing representation of the city of the future, we are inevitably drawn to popular culture media such as movies and graphic novels. For almost a century, movies in particular have proposed realistic constructs of future urban settlements along with the life associated with them. Based on a number of ideas expressed in motion pictures over the years about urban life in the future, one can argue that both past and recent predictions tend to be technologically optimistic but socially and environmentally pessimistic. This paper proposes to identify and discuss a number of challenges as well as opportunities associated with urban development in the next 100 to 200 years and present a series of urban visions to illustrate both positive and negative trends.
\end{abstract}

In the context of a continued and unprecedented growth for the past 50 years in cities worldwide, the goal of this paper is to identify trends in urban development and offer urban visions of what the city of the future might be and look like. Considering that this considerable urban growth is likely to continue, it will bring a whole array of challenges, but also opportunities to improve upon the current quality of life in urban centers. To that end we will look at how society has already produced convincing visions of an urban future through popular media, and more specifically motion picture. We will also attempt to outline realistic trends and visions for the metropolis of the near future based on current technology, social issues and economic development already affecting our cities today.

Historically, and maybe especially since the Industrial Revolution, cities have been both a symbol of progress as well as alienation. In that context, just as urban centers have brought the hope of employment and higher wages, they have also been synonymous with an oppressive social and physical environment. In that regard, the 1927 movie Metropolis, by German director Fritz Lang, proposes a very pessimistic vision of the city of the future based 
on some of the changes brought by the industrial revolution. Within this construct, the city is conceived as a reflection of society. Most of the urban population is composed of an oppressed working class who lives and works in poor conditions, while a small elite enjoys a life of leisure and luxury. Metaphorically, the working masses work for the city to make it function so that it can be enjoyed by a select few. In that context, the city itself becomes the symbol of alienation with its massive buildings and machines. Most of its physical environment is dark, uncomfortable and depressing. Metropolis makes sense as a social criticism of its time as the society of the day is still very much engaged in the industrial revolution. The idea of the city as a symbol of alienation, but also as a physical environment that is oppressive can be traced to the urban planning associated with the industrial revolution of the late 19th century and the 20th century modernism. Large urban housing projects such as the Cité Radieuse and the Plan Voisin by architect Le Corbusier are in fact a testament to the urban planning ideas of that time with their repetitive and out of scale designs. With a similar message, the 1965 movie Alphaville by French director Jean Luc Godard also addresses issues of social disconnect and personal alienation. It also uses the ubiquitous aesthetic of the modern architecture and urban planning of the 1950s and 1960s of Paris and its suburbs to represent alienation. Both Metropolis and Alphaville can be described as movies using in one case an imaginary urban context and in the other a real one as a vehicle for social criticism. In both cases, the premise is that cities have been designed by technocrats with little to no concern for the well-being of most of their inhabitants. In contrast, the urban environment created in Blade Runner (Ridley Scott 1982) presents a futuristic city that appears to have grown incrementally and organically to form a seemingly unplanned maze. The city as a whole seems to be functioning, but again its physical environment does not seem very conducive to a harmonious life. In that context, the city of the future is a result of an unplanned growth characterized by a network of overcrowded and rundown buildings. That vision, though decidedly pessimistic, is based on the understanding that cities evolve incrementally and over relatively long periods of time. In the more recent Ready Player One (Steven Spielberg 2018), we discover an urban environment alike of a waste field where a derelict urban world has been replaced by a virtual alternative. Again, just like Metropolis, Ready Player One is presenting an urban environment, which has very little quality for human life.

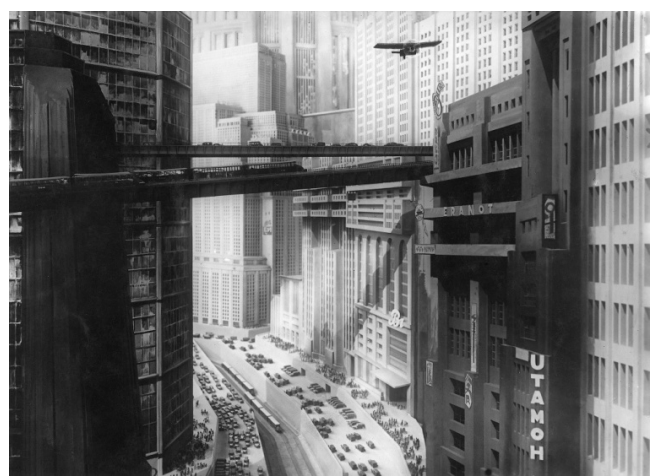

Fig. 1. Metropolis by Fritz Lang. 1927.

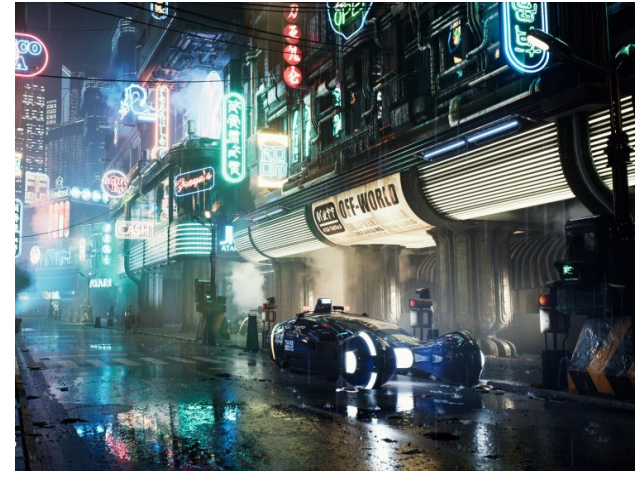

Fig. 2. Blade Runner by Ridley Scott. 1982.

As we compare the ways in which the city of the future is represented in these films over a period of almost 100 years, it is interesting to note that the city, as an image of society, becomes a symbol of its bad deeds and failures. The urban visions presented in these movies, as though they were representative of different times, seem to share the idea that society is firmly engaged in technological progress but has neglected to provide adequate solutions 
with regards to the quality of the urban environment, affordable housing, access to nature, air quality and the overall human experience in the urban world. Or, to put it more accurately, a small portion of the urban population has access to quality housing and urban environments, while the vast majority of urban residents does not. These movies share the idea of the city of the future as a dystopia and a microcosm, which displays great inequalities. Using the physical environment of the city as an expression of society itself, these movies propose a pessimistic vision of the future as there are undoubtedly a number of serious challenges ahead.

Now if we consider for a moment the cities of our times, one can summarize a number of these challenges we can actually observe. As there continues to be global trends of positive migration towards cities both in developed and developing countries, the sheer size of cities has become an issue. In fact, once urban structures reach a certain size, providing a number of basic services turns into complex problems. For example, food and water supplies as well as garbage collection systems, become especially challenging for very large cities. Coordinating commercial, public and private transportation systems poses a number of problems, including environmental issues. The construction of new buildings requires considerable updates and improvements in terms of infrastructure, and so do transportation networks. As a very visible consequence of the growth and densification of large urban areas worldwide, transportation in these cities has turned into huge challenges. In that context, providing access to clean air, parks and meaningful spaces for urban residents remains a challenge in many cities around the world.

\section{Housing affordability and urban density}

Though decent and affordable housing is key to the well-being of people, cities are struggling to meet that need in both developing and advanced economies. If current trends in urbanization and income growth persist, the number of urban households that live in substandard housing could grow from 330 million to 440 million by 2025 . This would mean that the global affordable housing gap would affect one in three urban dwellers or approximately 1.6 billion people. In that scenario, the disproportionate cost of housing relative to overall life cost would make other essential services, such as healthcare, unaffordable for urban households (Woetzel 2017).

Billions of people in cities around the world are faced with a great challenge whenever they attempt to find a new home. From Tokyo to Medellin, housing costs are creating financial stress for a vast majority of the world's urban residents. The cost of owning or renting a dwelling has risen far faster than incomes in most countries, especially in large cities, where many people want to live and where job opportunities are concentrated. This issue stems from the fact that there is a large disproportion between supply and demand. Population growth, a steady trend toward urbanization, and overall increase in global incomes are all contributing to a steady demand increase. The number of housing units in urban centers around the world has not significantly increased to keep up with this surge in demand. It would take a serious increase in the number of housing units produced to achieve greater affordability. But this is no easy task considering the sheer number of people moving to urban areas.

One of the first issues to tackle is to find vacant sites across these cities, and preferably along public transportation corridors. For example, sites that are underutilized can be identified as priorities for redevelopment. Incentives, such as investment in public parking and other types of infrastructure, can make these types of projects more attractive to 
developers. Another possible strategy, especially in very dense urban centers, involves building infill housing on vacant parcels. Even dense neighborhoods may have empty lots that could serve as viable sites. Other buildings, such as outdated sports facilities, military bases, or transit hubs, may also provide valuable land. Some cities may be able to convert derelict industrial sites and create large attractive mixed-use developments. Large unused industrial parcels can offer tremendous development potential. In addition to these potential solutions, a relatively new trend has emerged where cities can encourage the owners of single-family homes to add accessory dwelling units. Accessory dwelling units are by nature affordable because they use existing land, buildings, and infrastructure.

It is critical for congested cities to promote density along public transportation corridors rather than encourage sprawl and longer commutes. Transit-oriented development may involve redeveloping existing residential structures or encouraging new buildings by permitting higher floor-space ratios, loosening height restrictions, or allowing greater density in specific target zones. These zones can be selected to promote local objectives, such as reduced dependence on private vehicles or the development of mixed-use, pedestrianfriendly cityscapes. In many cases, cities may not even need to increase density thresholds. They can build out on residential parcels that are not taking advantage of currently allowed density (Woetzel 2017).

As cities can create incentives for new development and make land available, the whole design and construction industry needs to increase efficiency and streamline production. In fact, when compared to other sectors of the economy, such as services and industrial production, productivity in the construction industry has remained stagnant for years. A big boost in productivity could come with the concept of a manufacturing-inspired massproduction system. Prefabrication presents a huge potential for a broad array of building types and bring a series of improvements with regards to material waste, workers' safety, quality control and overall lower costs. This involves more standardized elements, panels manufactured and assembled off-site, and limited finishing work conducted on-site. Countries such as Sweden already produce a large portion of their housing stock using various degrees of prefabrication. Other recent technological developments, such as 3D printing using composite materials or concrete mixes, have seen exciting developments and are starting to be applied in large scale projects. Saudi Arabia, for example, is looking at building a large real estate project in Dubai using a 3D printing concept. Considering that, around the world, buildings' heating and cooling account for 35 to 60 percent of total energy demand and produce nearly 40 percent of emissions, the effort to reduce energy use and emissions, from buildings will continue to remain an important challenge to solve. 


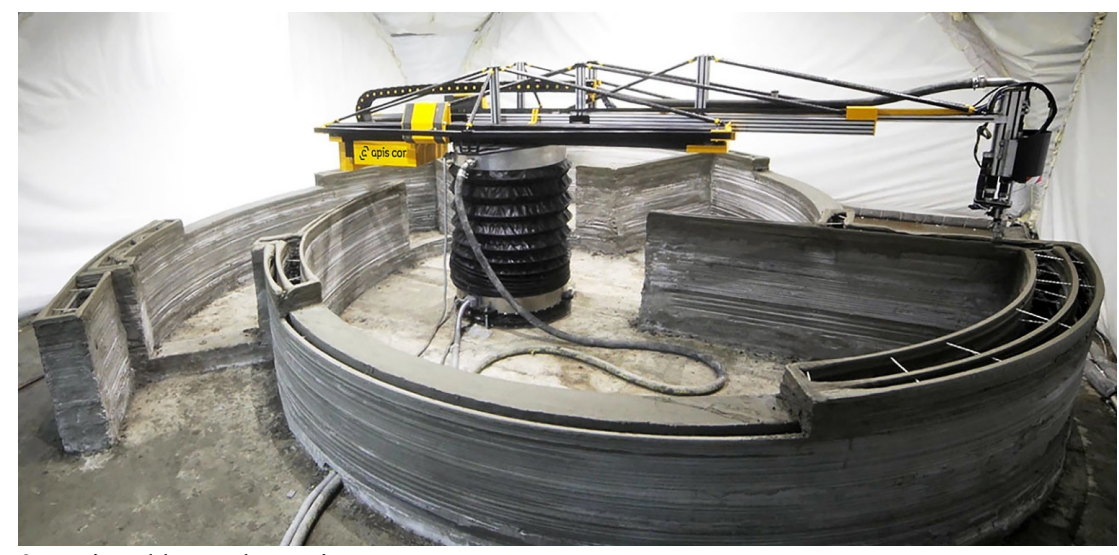

Fig. 3. 3D printed house by Apis Cor.

\section{Transportation and mobility}

A number of trends are influencing urban-mobility systems around the world, such as shared mobility, autonomous vehicles, electric vehicles and public transit. Trends, like vehicle electrification and the development of autonomous-driving technology, relate directly to mobility and are in turn pushing towards the decentralization of energy systems, as modes of transportation come to rely more and more on electricity as an energy source. Ride-hailing services have grown rapidly over the past few years and now compete not only with traditional car-sharing and car-pooling providers, but also with public transit and private vehicle ownership. Investments in ride-hailing companies, such as Uber and Lyft, have taken off, too, more than doubling to $\$ 11.3$ billion in 2015 from $\$ 5.3$ billion in 2014 (Gao 2016). Advances in autonomous-driving technology seems promising with regards to road-safety, transportation cost and access to mobility. Autonomous vehicles will turn driving time into free or more productive time. Autonomous vehicles could also lead to higher overall vehicle mileage, as people take advantage of their convenience by making more trips or even sending autonomous vehicles to run errands for them. Globally, electric-vehicle sales have risen quickly, from 50,000 in 2011 to nearly 450,000 in 2015. Purchase subsidies, falling battery costs, fuel-economy regulations, and product improvements have contributed to the increase. Bloomberg New Energy Finance estimates that battery costs will drop below $\$ 100$ per kilowatt-hour in the next decade. If that happens, electric vehicles should achieve cost competitiveness with conventional vehicles (Gao 2016). On the other hand, the widespread of information technology applications into vehicles and infrastructure will generate data with a variety of uses. For commuters, software systems can facilitate trip planning and guide autonomous vehicles based on real-time conditions. Transit authorities could use the same data to analyze the movement of people and vehicles, identify bottlenecks, adjust services, and make long-term transit plans. Cities around the world are expanding and improving their public-transit networks. Adding autonomous features to transit vehicles may reduce operating costs, while new deployment models, such as fleets of shared vehicles, can make transit more flexible and accessible. The United Nations Population Division projects that the world's urban population will increase by more than two-thirds by 2050 (UN Report 2014). Such an increase of people in motion could put more strain on city roads that are already struggling to keep up with increases in vehicle miles. But infrastructure upgrades that favor public or shared transit and bicycling could reinforce a shift away from car ownership.

In a broader context, integrated mobility systems should improve the lives of city dwellers in a number of ways. One is environmental quality. As more commuters shift to electric 
vehicles, shared mobility services, and public transit, emissions of carbon dioxide, nitrogen oxides, and fine airborne particulates in cities should go down. This will contribute to reducing health problems associated with air pollution.

When it comes to urban commercial transport, a number of solutions have been identified, such as order grouping, route optimization, and night deliveries, which could be implemented more or less immediately. Others, such as the use of robots, and autonomous ground vehicles, are currently in research and development, but likely years away from large-scale applications (Bouton 2017). A large portion of the current transportation networks of our cities will most likely remain though the nature of the vehicles involved will change. The use of low and no-emission vehicles is a critical part of solving the transportation and mobility challenge while at the same time reducing greenhouse gas emissions and improving air quality for urban residents.

\section{Sustainability and resilience}

The unprecedented urbanization we have experienced in the last five decades has primarily taken place in developing countries and areas exposed to natural hazards, such as riverbanks and coast lines. The fact that a number of these urban development projects have consisted of informal and unplanned settlements exacerbates existing challenges and leaves cities more vulnerable to natural hazards. The idea of concentrating large numbers of people and assets geographically logically increases the potential impact of natural disasters, especially in the context of increasing extreme weather events. Large urban settlements can therefore suffer devastating events in terms of human lives lost, infrastructure and economic livelihood. The poor segments of the population are particularly exposed, as they tend to live in lesser quality housing and lack the necessary safety nets to recover from both economic and environmental disasters. Therefore, the major resilience challenges of our times, be it poverty reduction, natural disasters, climate change, environmental sustainability and social inclusion will take place in our cities.

In addition to the threats generated by climate change, the continuous population migration from precarious parts of the world, such as Africa and the Middle East, to more stable developed countries are creating additional strain to existing urban centers. The recent impact of Hurricane Michael in October 2018 on the Florida Panhandle shows how even a relatively well-developed urban area can suffer tremendous infrastructure and economic loss in the context of unexpected climatic events. The need for human settlements in general and urban centers in particular to gain a certain level of resilience has emerged as a crucial challenge in the last decade. The concept of urban resilience can be defined as the ability of an urban system, including its inhabitants, to maintain continuity through stress and disasters whether they are man-made, or weather-related. Discussions on urban resilience have focused primarily on three specific threats, climate change, natural disasters and terrorism (Coaffee 2008). One key component of addressing resilience lies in the ability of cities to become more sustainable. In fact, more and more cities are being evaluated in terms of their ability to adapt to changing conditions (Ayooh 2016) and against the notion of cities as highly complex adaptive systems. In that context, urban planning would move away from a traditional approach based on geometric plans to an approach informed by network science.

Climate-related challenges, such as flooding, heat waves and droughts, have been found to provide a threat to approximately 1.7 billion people, with a combined GDP of USD 35 trillion according to a recent study (UN Habitat 2016). Heat waves, which have in recent years affected a large number of urban areas across temperate climatic zones, have resulted 
in significant deaths along with spikes in electric demand, forest fires, air pollution and reduced biodiversity. Agricultural losses from heat and drought can in turn have severe consequences in terms of food access and social stability. In that context, the direct fatalities linked to heat waves are statistically concentrated in urban areas because of inadequate housing conditions and the urban heat island effect. The urban heat island effect has been known to generate daytime temperatures up to $10^{\circ} \mathrm{C}$ higher in a city and between 5 to $6^{\circ} \mathrm{C}$ warmer at night. The primary factor for this phenomenon is the presence in cities of a number of materials, which absorb and store heat much more effectively than in rural areas. Urban geometry also plays a role as tall buildings can reduce wind and air movement therefore limiting convection cooling (Oke 1982). With regards to urban heat island effect, a number of strategies has been identified and is currently being implemented. The idea is to increase the amount of natural cover within the city and increase surface refractivity. Trees are especially effective in that regard, as they provide shading to both buildings and ground's surfaces and contribute to creating pedestrian friendly spaces with cooler temperatures. Another important strategy aimed at reducing the urban heat island effect consists in increasing the albedo or light reflectiveness of urban surfaces especially horizontal planes such as roofs.

In terms of flooding, risk urban areas have seen increased occurrences of serious flooding due to the effects of climate change. The cities of Brisbane, Australia in the summer 201011, New Orleans, USA in 2005 and Nimes, France in 1998 have all experienced catastrophic floods. A broader approach consisting in replacing as many non-porous surfaces with more porous green spaces can certainly help. Typical grassed areas and gardens can be complemented by high absorption bioswales that replicate natural environments such as swamps. The deeper the soil, the more rainwater it can absorb. One effective strategy simply consists in creating enough space for the excess water generated by a storm. Flood plain clearance, which removes structures and pavement from flood plains and promotes a natural environment, is a logical and nature-inspired solution that has a lot of benefits. It provides large natural areas capable of absorbing large quantities of water in order to limit or avoid the flooding of adjacent urban areas (Tanner et al. 2009). As another potential strategy, green roofs have gained popularity in the past 15 years, though their impact is typically limited due to limitation of depth and weight. In certain situations where cities are on flood plains or along rivers and coasts, levees and other flood barriers may remain an indispensable tool. Unfortunately, this type of equipment and infrastructure is typically out of reach for some of the most vulnerable communities in the developing world.

\section{Urban environment quality}

As we mentioned the urban heat island effect and flooding as urban vulnerabilities, their occurrences present a number of opportunities aimed at improving the physical environment of cities. Historically, the physical growth of cities around the world has been primarily driven by economic development, therefore leading to the massive building structures we can experience today. One can argue that the development of cities has been a constant balance between economic pressure and livability. The two issues are very much tied, as livability is an important factor for making cities attractive from an economic standpoint. The greatest and most livable cities around the world are known for providing people with the ability to physically interact with their environment with such amenities as vibrant streets, parks, plazas and gardens. Being physically engaged with the environment where one lives and the ability to connect to nature and the outside is a basic human need. Therefore, and in order to remain competitive and attractive, cities have to commit to creating and nurturing positive, diverse and safe urban spaces, as well as a clean and healthy overall environment. 


\section{A few possible scenarios}

The cities of the future, along with their suburbs, will be bigger and denser as land is a finite resource and more and more people will continue to migrate towards them. Real estate value will continue to grow along with speculation. Commute time will remain, but its quality may improve due to more efficient mass transit and the increased flexibility of shared and public transportation. Large high-tech buildings will continue to be built by public entities and large corporations, along with micro un-planned developments. Cities will likely remain less and less affordable. When it comes to the space of the city and more specifically that of the street, one can wonder who will prevail between vehicles and pedestrians. Hopefully, we will reach some type of status quo. The existing roads will most likely be used by automated electric vehicles to transport heavy things from food to construction materials and everything in between. Most deliveries will be scheduled at off-peak times and at night so as to improve flow and efficiency. Private and shared vehicles would use the same roads as commercial and utility vehicles, though at some point one could see additional roads being built above the network of existing streets. More utilitarian traffic would occur at ground level, as higher levels would offer a more enjoyable experience for commuters.

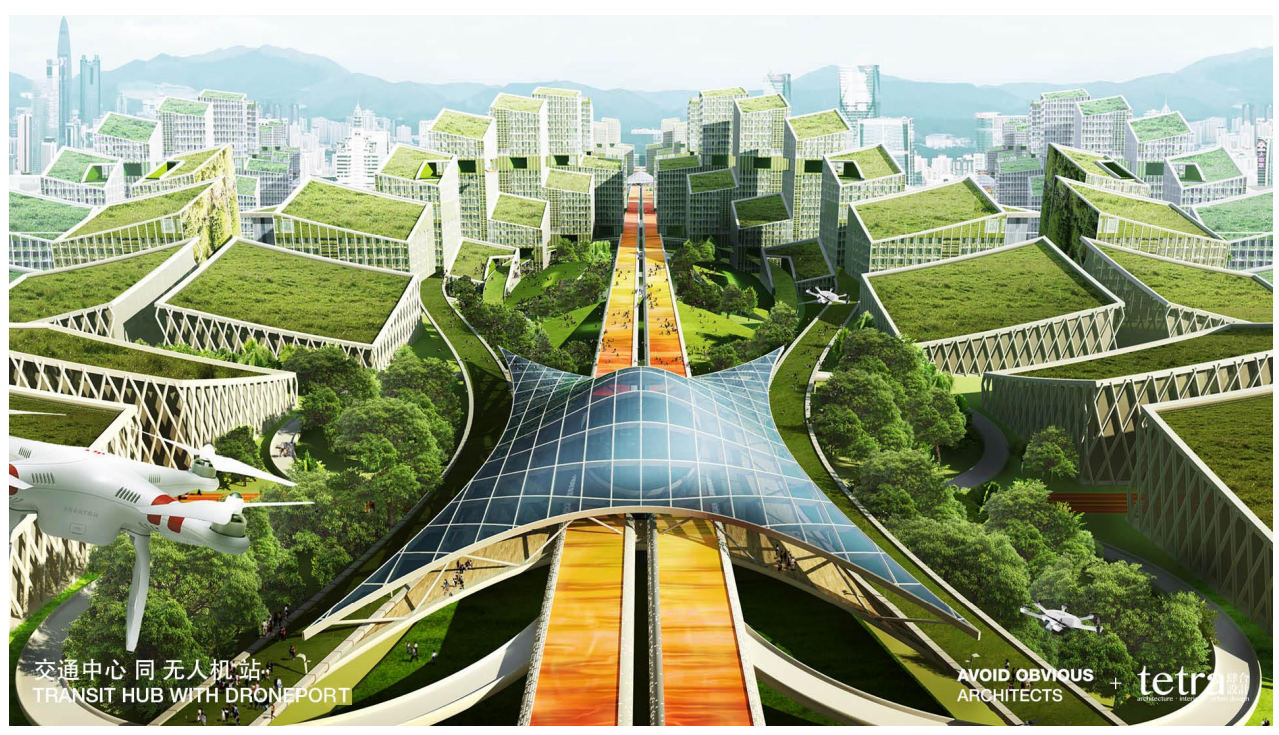

Fig. 4. Shenzhen master plan. Avoid obvious architects and Tetra.

At some point, the ground street level may not be available to pedestrians. A compromise would consist in creating dedicated multilevel transportation axes while dedicating other streets purely to pedestrian access. We are already seeing that trend when it comes to pedestrian streets worldwide. If the space of the streets at ground level was to change in nature and become unsafe, as suggested by a number of cinematographic representations, then the traditional street experience would be lost (e.g. 5th Element, Blade Runner, Next Gen). In that case, the basic relationship of people with the ground and all its important connotations would also be lost. The wealthy-enough urbanites would commute via dronetype vehicles on a system of carefully established elevations similar to the way commercial aviation currently operates. Similarly, small packages may be transported by drones along specifically determined aerial corridors. The use of lightweight private electric-powered drone-type vehicles will inevitably see an increase but will most certainly remain costly. 
Buildings themselves will be built and operated more efficiently. They will be assembled on-site using pre-fabricated components and will have high-tech envelopes able to react to the exterior environment with regards to light, wind and water. They will be self-cleaning and every exterior surface will be designed to collect solar energy. In parallel to high-tech buildings, cities may see the re-introduction of nature-inspired ecosystems within their footprint in order to mitigate water run-off, heat waves and provide meaningful green spaces for urban residents. Overall, the physical structure of the city will harvest energy and water, and the shift towards everything electric will help with controls, efficiency and creating a much cleaner environment for urban dwellers. Urban planners will study urban morphology to offset negative weather patterns (heat gain, excessive wind loads) and enhance positive ones (cooling breezes, shading). Technological progress at every level of society will contribute to making things more affordable. Prefab technology should increase affordability for urban housing as long as adequate public policies continue to support it. Technologies such as digital fabrication and large-scale 3D printing along with advanced sustainable practices will lower construction and operating costs, therefore lowering overall costs. There is no doubt that technology and automation will have an effect on cost, but they will also influence job access. The hope is that overall life conditions will raise across various social levels of society so that cities can remain ethnically, socially, economically and culturally diverse. Social inequalities will most likely remain, but there is hope that with the advent of new technologies and efficiencies more people will be afforded an improved basic standard of living. As less and less physical tasks will require the need of human workers the emergence of a universal basic income seems inevitable. In the context of intense technological changes, the big question regarding the city of the future is whether it will be able to remain a vibrant and healthy place to live while continuing to be a crucial economic driver.

\section{References}

1. J. Woetzel, S. Ram, S. Peloquin, M. Limam, J. Mischke. Housing affordability: a supply-side tool kit for cities. Executive briefing, Mc Kinsey Global Institute (2017)

2. P. Gao, H.W. Kaas, D. Mohr, D.Wee. Disruptive trends that will transform the auto industry. Executive briefing, Mc Kinsey Global Institute (2016)

3. UN, Department of Economical Social Affairs, Population Division, esa.un.org. (2014)

4. S. Bouton, E. Hannon, S. Knupfer, S. Ramkumar. The future of mobility: how cities can benefit. (2017)

5. Coaffee. Risk, resilience and environmentally sustainable cities. Energy Policy, 36 (12). (2008)

6. UN Habitat. World cities report 2016: emerging futures. (2016)

7. T.R. Oke, The energetic basis of the urban heat island. Quarterly Journal of the royal meteorological society. (1982)

8. T. Tanner, T. Mitchell. Urban governance for adaptation: assessing climate change resilience in ten Asian cities. (2009) 